\title{
The electrical properties of nanocrystalline $\mathrm{Cu}-\mathrm{Al}_{2} \mathrm{O}_{3}$
}

\author{
M. Orolínová ${ }^{1 *}$, J. Ďurišin ${ }^{1}$, K. Ďurišinová ${ }^{1}$, Z. Danková ${ }^{2}$, M. Besterci ${ }^{1}$ \\ ${ }^{1}$ Institute of Materials Research of the Slovak Academy of Sciences, Watsonova 47, 04353 Košice, Slovak Republic \\ ${ }^{2}$ Institute of Geotechnics of the Slovak Academy of Sciences, Watsonova 45, 04353 Košice, Slovak Republic
}

Received 13 April 2015, received in revised form 30 April 2015, accepted 25 June 2015

\begin{abstract}
Nanocrystalline (nc) $\mathrm{Cu}$ powders with $\mathrm{Al}_{2} \mathrm{O}_{3}$ dispersoid (1-5 vol.\% $\mathrm{Al}_{2} \mathrm{O}_{3}$ ) were prepared by combination of phase transformations with intensive milling and the following consolidation by pressing, sintering and hot extrusion. The electrical properties of the composites were analysed in relation to their microstructure and strength. The main contribution to the electrical resistivity was attributed to the grain/crystallite size of $\mathrm{Cu}$ matrix. The fraction of $\mathrm{Fe}$ impurities dissolved within the $\mathrm{Cu}$ matrix and the amount of $\mathrm{Al}_{2} \mathrm{O}_{3}$ particles in the $\mathrm{Cu}$ matrix affected the electrical resistivity remarkably. The optimal combination of electrical and strength properties can be achieved by cut-down of $\mathrm{Al}_{2} \mathrm{O}_{3}$ content and by optimization of dispersoid distribution in the matrix.
\end{abstract}

$\mathrm{K}$ e y words: nanocrystalline $\mathrm{Cu}-\mathrm{Al}_{2} \mathrm{O}_{3}$ alloys, dispersion strengthening, electrical properties, thermal stability

\section{Introduction}

The potential of nano-materials to exhibit an unusual combination of properties has led to extensive research activities since last two decades. Recently, alloys exhibiting high mechanical strength together with high electrical conductivity at elevated temperatures are in increasing demand [1]. A significant amount of research effort has been expanded by studying and understanding the intrinsic fabrication characteristics, mechanical and electrical properties characterization of nanostructured copper [2]. The cold deformation hardened pure copper or precipitates hardened copper alloys such as $\mathrm{Cu}-\mathrm{Cr}$ and $\mathrm{Cu}-\mathrm{Cr}-\mathrm{Zr}$ alloys are softened easily [3]. It is necessary to develop a novel material with a high softening temperature, high electrical conductivity, and high strength at elevated temperatures. Oxide dispersion strengthened (DS) composites on copper base are the most promising systems for such an application [4]. In recent years studies on the synthesis and characterization of alumina DS copper have attracted the interest of scientists [5]. The presence of a fine dispersion of $\mathrm{Al}_{2} \mathrm{O}_{3}$ particles in $\mathrm{Cu}$ matrix improves the hardness and strength of this material at room and higher temperatures. The nc alumina
DS $\mathrm{Cu}$ possesses the beneficial properties, exploiting both grain boundary strengthening and dispersion strengthening [6]. In addition, high thermal stability of $\mathrm{Al}_{2} \mathrm{O}_{3}$ particles against the dissolving, which thus retain their ability to obstruct dislocation motion and inhibit the grain growth at temperature even close to the melting point of the $\mathrm{Cu}$ matrix, also contributes to high strength of composites $[7,8]$.

Many manufacturing processes have been utilized to produce the $\mathrm{Cu}-\mathrm{Al}_{2} \mathrm{O}_{3}$ composites, like mechanical alloying, internal oxidation, spray forming, etc. $[9,10]$. However, these processes have their limitation and often suffer from non-uniform distribution of dispersoid particles, which negatively influences the mechanical and electrical properties. The mechanochemical routes have recently emerged as a potential technique for the synthesis of DS metal matrix composites [1].

In the present study, the electrical properties of nc $\mathrm{Cu}-\mathrm{Al}_{2} \mathrm{O}_{3}$ alloys with $1-5$ vol.\% of secondary phase are discussed in relation to the microstructure and strength. These alloys were developed primarily for spot welding electrode material application. The high strength, desirable electrical conductivity and good thermal stability of the electrode material make it possible for increasing the electrode durability.

*Corresponding author: tel.: +421-55-7922 467; e-mail address: $\underline{\text { morolinova@imr.saske.sk }}$ 
Ta ble 1 . The mean grain/crystallite size $(d)$ of the $\mathrm{Cu}-\mathrm{Al}_{2} \mathrm{O}_{3}$ nanocomposites

\begin{tabular}{cccc}
\hline & \multicolumn{3}{c}{$d$ grain/crystallite $(\mathrm{nm})$} \\
\cline { 2 - 4 } $\mathrm{Al}_{2} \mathrm{O}_{3}($ vol.\%) & & \multicolumn{2}{c}{ Compact } \\
\cline { 3 - 4 } & Powder & starting state & after annealing at $800^{\circ} \mathrm{C} / 1 \mathrm{~h}$ \\
\hline 1 & 36 & 95 & 99 \\
3 & 33 & 80 & 84 \\
5 & 29 & 73 & 76 \\
\hline
\end{tabular}

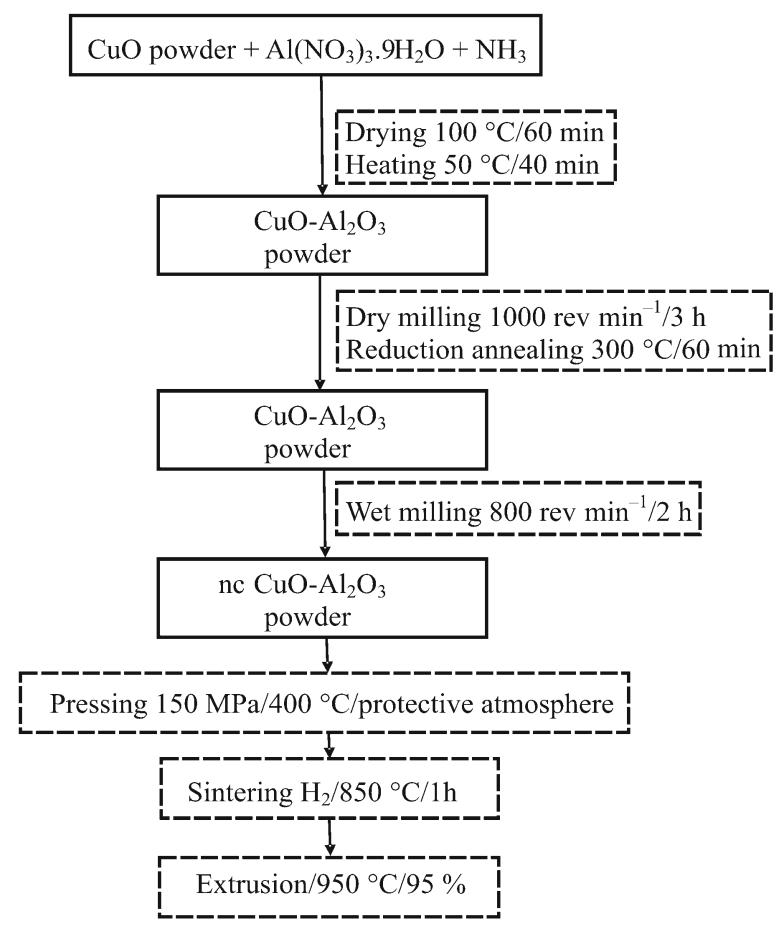

Fig. 1. Scheme of the $\mathrm{Cu}-\mathrm{Al}_{2} \mathrm{O}_{3}$ nanocomposites preparation.

\section{Experimental material and methods}

The experimental material was $\mathrm{nc} \mathrm{Cu}$ reinforced with 1,3 and 5 vol. $\% \mathrm{Al}_{2} \mathrm{O}_{3}$. The composite powders were prepared by the mechanochemical method based on the high energy ball milling in an attritor and chemical reduction by hydrogen [11], Fig. 1. The particles of $\gamma \mathrm{Al}_{2} \mathrm{O}_{3}$ secondary phase were formed in the $\mathrm{Cu}$ matrix precursor $-\mathrm{CuO}$ powder. The $\mathrm{CuO}$ powder was prepared by annealing of electrolytic $\mathrm{Cu}$ powder (size range $<40 \mu \mathrm{m}, 0.0002 \mathrm{wt} . \%$ of $\mathrm{Fe}$ ). The $\mathrm{CuO}-\mathrm{Al}_{2} \mathrm{O}_{3}$ powder mixtures were dry ball-milled for $3 \mathrm{~h}$ at $1000 \mathrm{rev} \mathrm{min}^{-1}$, using the steel water cooled container and steel balls. The volume ratio of balls to powder was $5: 1$. The $\mathrm{Cu}-\mathrm{Al}_{2} \mathrm{O}_{3}$ powder mixtures arisen by the following reduction annealing were wet milled in ethanol for $2 \mathrm{~h}$ at $800 \mathrm{rev} \min ^{-1}$. The volume ratio of balls to powder was $5: 1$, too. The
Table 2. The amount of Fe in the examined powders

\begin{tabular}{ccc}
\hline \multicolumn{3}{c}{$\mathrm{Fe}($ wt.\%) } \\
\hline $\begin{array}{c}\mathrm{Cu} \\
\text { delivered state }\end{array}$ & $\begin{array}{c}\mathrm{CuO}-\mathrm{Al}_{2} \mathrm{O}_{3} \\
\text { after dry milling }\end{array}$ & $\begin{array}{c}\mathrm{Cu}-\mathrm{Al}_{2} \mathrm{O}_{3} \\
\text { after wet milling }\end{array}$ \\
\hline 0.0002 & $0.041 \pm 0.006$ & $0.065 \pm 0.008$ \\
\hline
\end{tabular}

final $\mathrm{Cu}$ powder matrix was characterized by average grain/crystallite size ranged in the interval from 36 to $29 \mathrm{~nm}$ for the 1 vol. $\% \mathrm{Al}_{2} \mathrm{O}_{3}$ and 5 vol. $\% \mathrm{Al}_{2} \mathrm{O}_{3}$, respectively, Table 1. During the milling, the powder was contaminated with $\mathrm{Fe}$ impurities from the abrasion of milling balls and body of attritor. The amount of Fe was approximately equal in all examined powders (before compaction) and was determined by chemical analysis, Table 2 . The following compaction process consisted of powder pressing, sintering and hot extrusion, Fig. 1.

The size and morphology of the secondary phase in the experimental compacts were observed by a transmission electron microscopy (TEM) TESLA BS 500 by the method of two-stage carbon replicas. The X-ray diffraction patterns (XRD) of the experimental samples were measured by diffractometer Philips X'Pert Pro equipped with the Ni-filtered $\mathrm{CuK} \alpha$ radiation using the positional sensitive detector X'Celerator (40 kV and $40 \mathrm{~mA}$ ). The XRD spectra were measured in the position range from $40^{\circ}$ to $100^{\circ}$ $(2 \theta)$ with a step size $0.03^{\circ}$ and step time $8 \mathrm{~s}$. The average grain/crystallite size was determined using the Williamson-Hall equation. The Williamson-Hall equation separates the effects of size and strain in the crystals and is convenient for the estimation of crystal size of deformed materials [7].

The electrical resistivity was measured by a fourprobe technique using the HP $6612 \mathrm{C}$ digital multimeter. The total porosity was calculated from the density measurements. The density of compacts was determined by the Archimedes method. The theoretical value of density was calculated by the rule of mixtures, with density values for copper $\left(8.96 \mathrm{~g} \mathrm{~cm}^{-2}\right)$ and 


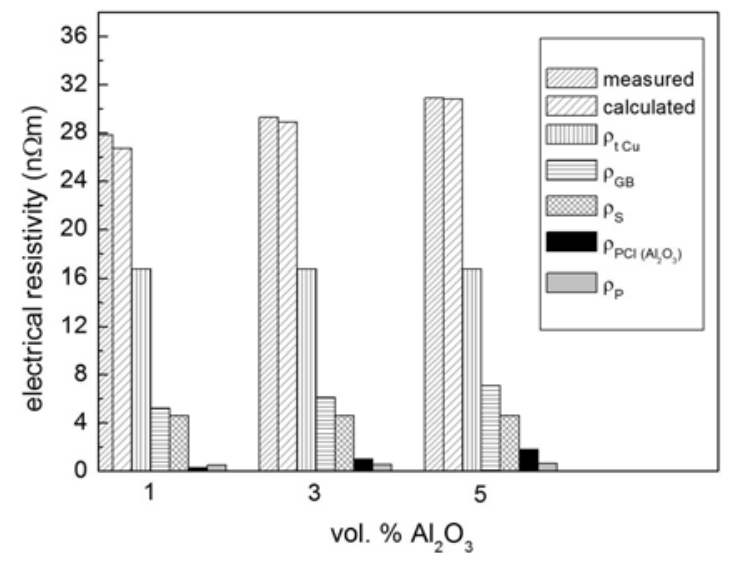

Fig. 2. The electrical resistivity of the $\mathrm{Cu}-\mathrm{Al}_{2} \mathrm{O}_{3}$ nanocomposites with a different amount of dispersoid.

alumina $\left(3.42 \mathrm{~g} \mathrm{~cm}^{-2}\right)$. The values of yield strength at room temperature were evaluated by the static tensile test STN EN ISO 6892-1 performed by the TIRATEST 2300 test machine. The thermal stability of the composites was studied after the isothermal annealing at $800^{\circ} \mathrm{C}$ for $1 \mathrm{~h}$ in the air.

\section{Results and discussion}

\subsection{Electrical properties}

\subsubsection{Contribution of various factors to electrical resistivity}

In this section, the contribution of various factors to the electrical resistivity of $\mathrm{nc} \mathrm{Cu}$ composites is formulated quantitatively. The measured value of resistivity is dependent on the amount of dispersoid and ranged from 27.8 to $30.9 \mathrm{n} \Omega \mathrm{m}$, Fig. 2. As the higher content of secondary phase was present in the composite, a higher value of resistivity was measured. The electrical resistivity $\rho$ of metals is generally described by Matthiessen's rule:

$$
\rho=\rho_{\mathrm{t}}+\rho_{\mathrm{D}}
$$

where $\rho_{\mathrm{t}}$ is a temperature-dependent contribution from the thermal vibration and $\rho_{\mathrm{D}}$ is a contribution from the lattice defects and impurities, which is independent of the temperature. The electrical resistivity of pure $\mathrm{Cu}, \rho_{\mathrm{tCu}}$ is $16.7 \mathrm{n} \Omega \mathrm{m}[12,13]$. In the composite material the part $\rho_{\mathrm{D}}$ can be described as an addition to several contributions:

$$
\rho_{\mathrm{D}}=\Delta \rho_{\mathrm{GB}}+\Delta \rho_{\mathrm{Pcl}}+\Delta \rho_{\mathrm{P}}+\Delta \rho_{\mathrm{Dl}}+\Delta \rho_{\mathrm{S}}
$$

where $\Delta \rho_{\mathrm{GB}}$ means a contribution of grain boundaries, $\Delta \rho_{\mathrm{Pcl}}$ of particles of the secondary phase, $\Delta \rho_{\mathrm{P}}$ of porosity, $\Delta \rho_{\mathrm{Dl}}$ of dislocations, and $\Delta \rho_{\mathrm{S}}$ of impurity atoms in solid solution [14].

(a) By increasing of the secondary phase content, the value of mean grain/crystallite size of $\mathrm{Cu}$ matrix decreased. It changed from $95 \mathrm{~nm}$ for 1 vol. $\% \mathrm{Al}_{2} \mathrm{O}_{3}$ to $73 \mathrm{~nm}$ for material with 5 vol. $\% \mathrm{Al}_{2} \mathrm{O}_{3}$, Table 1 . Consequently, a high contribution to the electrical resistivity from the grain/crystallite boundaries can be assumed [15]. The presence of the $\mathrm{Cu}$ grain/crystallite boundaries increases the electrical resistivity according to the following relation [16]:

$$
\Delta \rho_{\mathrm{GB}}=\frac{2}{3} \rho_{\mathrm{Cu}-\mathrm{GB}}\left(\frac{S}{V}\right)
$$

where $\rho_{\mathrm{Cu}-\mathrm{GB}}$ is the specific grain boundary resistivity and the value of $\rho_{\mathrm{Cu}-\mathrm{GB}}=3.12 \times 10^{-16}$ [14]. The ratio of $S / V$ is the grain boundary surface area $S$ per unit volume $V$, and this ratio can be approximated to be $2.37 / d_{\mathrm{G}}[14]$, where $d_{\mathrm{G}}$ is the $\mathrm{Cu}$ grain/crystallite size. The contribution to the electrical resistivity originated from the matrix grain/crystallite boundaries was relatively high in accordance with the assumption and ranged from 5.2 to $7.1 \mathrm{n} \Omega \mathrm{m}$, Fig. 2 .

(b) The contribution of volume fraction $f$ of alumina particles to resistivity can be estimated according to the equation [16]:

$$
\Delta \rho_{\mathrm{Pcl}}=\rho_{\mathrm{m}} \frac{3 f}{2(1-f)},
$$

where

$$
\rho_{\mathrm{m}}=\rho_{\mathrm{t}}+\Delta \rho_{\mathrm{GB}}+\Delta \rho_{\mathrm{Dl}}
$$

The contribution of dislocation density $(N)$ to the resistivity $\left(\Delta \rho_{\mathrm{Dl}}\right)$ is given by:

$$
\Delta \rho_{\mathrm{Dl}}=N r_{\mathrm{Dl}}
$$

where $\rho_{\mathrm{Dl}}$ is the specific dislocation resistivity and has a value of $0.8 \times 10^{-25} \Omega \mathrm{m}^{3}$ for copper [17]. The value of dislocation density was equivalent for all examined composites. The change of the dislocation density in dependence on the $\mathrm{Al}_{2} \mathrm{O}_{3}$ amount was relatively small. It increased from $1.9 \times 10^{14} \mathrm{~m}^{-2}$ for composite with 1 vol. $\% \mathrm{Al}_{2} \mathrm{O}_{3}$ to $4.4 \times 10^{14} \mathrm{~m}^{-2}$ for composite with 5 vol.\% $\mathrm{Al}_{2} \mathrm{O}_{3}$. In accordance with formula (6) the dislocation density $N$ that has contributed significantly to the resistivity (say more than $2 \%$ ) needs to be greater than $10^{16} \mathrm{~m}^{-2}[16]$. Also, the contribution of dislocation to the overall resistivity may be in experimental composites neglected. Then the contribution of the alumina particles to the resistivity in the experimental material ranged from 0.3 to $1.9 \mathrm{n} \Omega \mathrm{m}$ using Eqs. (4) and (5), Fig. 2. 
Table 3 . The electrical conductivity $(\lambda)$ and yield strength of the $\mathrm{Cu}-\mathrm{Al}_{2} \mathrm{O}_{3}$ nanocomposites

\begin{tabular}{|c|c|c|c|c|}
\hline \multicolumn{3}{|c|}{ Starting state } & \multicolumn{2}{|c|}{ After annealing at $800^{\circ} \mathrm{C} / 1 \mathrm{~h}$} \\
\hline $\begin{array}{l}\mathrm{Al}_{2} \mathrm{O}_{3} \\
\text { (vol.\%) }\end{array}$ & $\begin{array}{c}\lambda \\
(\% \mathrm{IACS})\end{array}$ & $\begin{array}{l}R_{\mathrm{p}} 0.2 \\
(\mathrm{MPa})\end{array}$ & $\begin{array}{c}\lambda \\
(\% \mathrm{IACS})\end{array}$ & $\begin{array}{l}R_{\mathrm{p}} 0.2 \\
(\mathrm{MPa})\end{array}$ \\
\hline 1 & 62 & 394 & 63 & 386 \\
\hline 3 & 59 & 501 & 59 & 490 \\
\hline 5 & 56 & 580 & 58 & 578 \\
\hline
\end{tabular}

(c) The density measurements confirmed that the porosity was not negligible of the experimental composites. The porosity increased with the higher amount of the secondary phase and ranged in the interval from 1.4 to $1.8 \%$. The contribution of porosity to the electrical resistivity can be estimated by the same manner as was done for the alumina particles [16]. The contribution of porosity to the electrical resistivity was not marked and ranged in the interval from 0.5 to $0.65 \mathrm{n} \Omega \mathrm{m}$, Fig. 2 .

(d) It is well known that a small volume fraction of dissolved species can lead to a major increase in the electrical resistivity. For the composites, there was a small but unknown volume fraction of dissolved $\mathrm{Fe}$ within the $\mathrm{Cu}$. This content was tried to deduce. The Fe amounts determined from the chemical analysis after the individual milling steps during the powder preparation are listed in Table 2. For all examined powders, the amount of $\mathrm{Fe}$ was approximately equal, and it increased with the increasing milling time. The room temperature solubility of iron in copper was determined some years ago by Hanson and Ford and stated to be about 0.2 wt.\% [16, 18]. The electrical resistivity increases linearly with the increasing atomic concentration of the solid solution according to [19]:

$$
\Delta \rho_{\mathrm{S}}=\beta c,
$$

where $c$ is the weight percentage of solid solution and the coefficient $\beta$ is the change in the electrical resistivity for $1 \mathrm{wt} . \%$ of solid solution. In the case of solid solution of $\mathrm{Fe}$ in $\mathrm{Cu}$ is $\beta=115 \mathrm{n} \Omega \mathrm{m}\left(\right.$ wt. $\%^{-1}$ ) [20], and so a solid solution of 0.065 wt.\% Fe (analysed in the final powders) gave the required increase in the resistivity by $11 \mathrm{n} \Omega \mathrm{m}$. This concentration of solid solution of $\mathrm{Fe}$ in $\mathrm{Cu}$ is acceptable: the $\mathrm{Cu}-\mathrm{Fe}$ phase diagram [18] shows that up to $1.5 \mathrm{wt} . \% \mathrm{Fe}$ is soluble in $\mathrm{Cu}$ at $800^{\circ} \mathrm{C}$ (the hot extrusion temperature).

The comparison of measured and calculated electrical resistivity suggested, however, that approximately 0.04 wt.\% of Fe was probably dissolved within the $\mathrm{Cu}$ matrix during the consolidation process. It can be concluded that the contribution of solid solution to the electrical resistivity was in this case in all experimental composites equal to $4.6 \mathrm{n} \Omega \mathrm{m}$. The remaining part of the mass fraction of chemically analysed $\mathrm{Fe}$ can occur in the form of oxides and therefore, its contribution to the electrical resistivity is negligible.

The final form of the $\rho_{\mathrm{D}}$ part for the equation for the electrical resistivity calculation $(\rho)$ of $\mathrm{nc} \mathrm{Cu}-\mathrm{Al}_{2} \mathrm{O}_{3}$ composites can be also expressed by the following superposition:

$$
\rho_{\mathrm{D}}=\rho_{\mathrm{GB}}+\Delta \rho_{\mathrm{S}}+\Delta \rho_{\mathrm{Pcl}}+\Delta \rho_{\mathrm{P}}
$$

According to the Eqs. (1) and (8), the electrical resistivity of experimental composites was calculated, Fig. 2.

\subsubsection{Possibilities of increasing the electrical conductivity}

The values of resistivity obtained in the $\mu \Omega \mathrm{cm}$ units were converted to $\%$ IACS conductivity values by the following formula [21]:

$$
172.41 / \text { resistivity }=\% \text { IACS. }
$$

The values of the electrical conductivity of nc $\mathrm{Cu}-\mathrm{Al}_{2} \mathrm{O}_{3}$ materials, Table 3 , were lower as those of conventional $\mathrm{CuCr}$ and $\mathrm{CuCrZr}$ electrode alloys (70$80 \%$ ) [3]. Minimum value of the electrical conductivity required for the copper-based alloys for hightemperature applications is $50 \%$ IACS [8]. Hence, the values of the electrical conductivity of $\mathrm{Cu}-\mathrm{Al}_{2} \mathrm{O}_{3}$ composites reinforced with 1,3 and 5 vol. $\%$ of the secondary phase were sufficient for the target applications. The higher electrical conductivity entails the smaller deterioration of electrodes and thereby the higher durability. According to the previous calculations, three relevant effects influenced the electrical conductivity of nc $\mathrm{Cu}-\mathrm{Al}_{2} \mathrm{O}_{3}$ composites. First, the grain boundaries size of $\mathrm{Cu}$ matrix was the dominant one, Fig. 2. The conductivity decreased with the decreasing grain/crystallite size, Tables 1,3 . By contrast, the size of small - nano grain/crystallites was very important in term of the strength of materials [7]. The strength increased with the decreasing grain/crystallite size, Tables 1 , 3. Second, the fraction of Fe impurities dissolved within the $\mathrm{Cu}$ matrix affected the electrical conductivity remarkably. The $\mathrm{Fe}$ amount in the $\mathrm{Cu}$ powder mainly depended on the 
milling time, milling ambient and the material composition of the milling balls. The enhance of the electrical conductivity of milled nc $\mathrm{Cu}$ composites could be achieved by reducing of the Fe abrasion by optimization of the milling process (for example by shortening the milling time, if an appropriate change of $\mathrm{Fe}$ milling balls for e.g. ceramics takes place). Third, an increasing amount of $\mathrm{Al}_{2} \mathrm{O}_{3}$ particles in the $\mathrm{Cu}$ matrix cuts the conductivity. In all examined composites the average size of the $\mathrm{Al}_{2} \mathrm{O}_{3}$ particles was approximately $5 \mathrm{~nm}$ in radius and they were distributed relatively homogeneously within the grains as well as on the matrix grain boundaries $[7,22]$. However, they showed the tendency to cluster formation [23]. This fact is illustrated in Figs. 3a-c. The volume of dispersoid (to $1 \mathrm{vol} . \%$ ) would be decreased if the conditions during the ball milling were regulated to ensure the superior homogeneous distribution of very fine $\mathrm{Al}_{2} \mathrm{O}_{3}$ particles and elimination of particles aggregates formation. The lower content of $\mathrm{Al}_{2} \mathrm{O}_{3}$ particles, effective from the strengthening point of view, would allow to achieve the optimal combination of strength and electrical properties. In the examined composites, the porosity did not influence the conductivity significantly.

\subsection{Thermal stability}

The thermal stability of electrical and strength properties was studied by the measurements after the annealing of material at $800^{\circ} \mathrm{C}$ for $1 \mathrm{~h}$ in the air. The wee improvement of the electrical conductivity was observed after this annealing, Table 3 . The yield strength remained practically unchanged after the annealing at $800^{\circ} \mathrm{C}$ for $1 \mathrm{~h}$ in comparison with the strength measured prior to the annealing in all composites, Table 3. This excellent thermal stability of material properties is dependent on the high thermal stability of the microstructure. This confirms the grain/crystallite size of $\mathrm{Cu}$ matrix that increased after the annealing only negligibly in all analysed materials, Table 1. A small increase of the value of electrical conductivity was due to the small increase in grain/crystallite size described above. It is possible to say that the $\mathrm{nc} \mathrm{Cu}$ composites are characterized by an excellent softening resistance and thermal stability of strength and electrical properties. Thermal stability of the examined materials up to 0.74 melting temperature of the matrix $\left(T_{\mathrm{m}}\right)$ is an additional value in term of improvement of serviceable life of electrodes.

\section{Conclusions}

This study examined the electrical properties of nano $\mathrm{Cu}-\left(1-5\right.$ vol. $\left.\% \mathrm{Al}_{2} \mathrm{O}_{3}\right)$ composites, prepared by the mechanochemical method, with the aim to enhance their electrical conductivity. The following con-


Fig. 3. TEM image of clusters of $\mathrm{Al}_{2} \mathrm{O}_{3}$ particles in the $\mathrm{Cu}-\mathrm{Al}_{2} \mathrm{O}_{3}$ nanocomposites.

clusions can be drawn:

- The electrical conductivity is mainly influenced by the grain size of the $\mathrm{Cu}$ matrix.

- The $\mathrm{Al}_{2} \mathrm{O}_{3}$ particles decrease the conductivity as a function of their volume fraction.

- The comparison of measured and calculated value of electrical resistivity suggested that in all examined composites approximately $0.04 \mathrm{wt} . \%$ of $\mathrm{Fe}$ was probably dissolved within the $\mathrm{Cu}$ matrix during the powder consolidation process. This amount affected the electrical conductivity decrease remarkably. 
- The electrical conductivity of $\mathrm{Cu}-\mathrm{Al}_{2} \mathrm{O}_{3}$ alloys could be increased by the elimination of $\mathrm{Fe}$ impurities in the powder, as well as by reduction of dispersoid volume. To maintain the high strength and excellent thermal stability, however, it is necessary to attain the most homogeneous distribution of $\mathrm{Al}_{2} \mathrm{O}_{3}$ particles in the $\mathrm{Cu}$ matrix. All this is possible by optimization of powder milling process.

\section{Acknowledgements}

The work was supported by the Slovak National Grant Agency under the VEGA projects 2/0128/13, 2/0114/13 and $2 / 0118 / 14$.

\section{References}

[1] Chandrasekhar, S. B., Sudhakara Sarma, S., Ramakrishna, M., Sures Babu, P., Rao, T. N., Kashyap, B. P.: Mater. Sci. Eng. A, 591, 2014, p. 46. doi:10.1016/j.msea.2013.10.074

[2] Gupta, M., Tay, A. A. O., Vaidyanathan, K., Srivatsan, T. S.: Mater. Sci. Eng. A, 454-455, 2007, p. 690. doi:10.1016/j.msea.2006.11.099

[3] Li, M.: Comprehensive Nuclear Materials, 4, 2012, p. 667. doi:10.1016/B978-0-08-056033-5.00122-1

[4] Tian, B., Liu, P., Song, K., Li, Y., Liu, Y., Ren, F., Su, J.: Mater. Sci. Eng. A, 435-436, 2006, p. 705. doi:10.1016/j.msea.2006.07.129

[5] Simchi, H., Simchi, A.: Mater. Sci. Eng. A, 507, 2009, p. 200. doi:10.1016/j.msea.2009.01.037

[6] Nachum, S., Fleck, N. A., Ashby, M. F., Colella, A., Matteazzi, P.: Mater. Sci. Eng. A, 527, 2010, p. 5065. doi:10.1016/j.msea.2010.04.070

[7] Orolínová, M., Durišin, J., Durišinová, K., Danková, Z., Besterci, M., Ďurišin, M., Szabó, J.: Kovove Mater., 52, 2014, p. 395.

[8] Rajkovic, V., Bozic, D., Jovanovic, M. T.: J. Alloys Compd., 459, 2008, p. 177. doi:10.1016/j.jallcom.2007.04.307
[9] Rajkovic, V., Bozic, D., Stasic, J., Wang, H., Jovanovic, M. T.: Powder Technol., 268, 2014, p. 392. doi:10.1016/j.powtec.2014.08.051

[10] Zhang, X. H., Li, X. X.: Int. J. Min. Met. Mater., 21, 2014, p. 1115. doi:10.1007/s12613-014-1016-4

[11] Orolínová, M., Durišin, J., Medvecký, L., Durišinová, K.: J. Mater. Sci. Lett., 20, 2001, p. 119. doi:10.1023/A:1006730016429

[12] ASM Handbook. Properties and Selection: Nonferrous Alloys and Special-Purpose Materials. Vol. 3. Materials Park, ASM International 2002.

[13] http://hyperphysics.phy-astr.gsu.edu/hbase/Tables/ rstiv.html

[14] Botcharova, E., Freudenberger, J., Schultz, L.: Acta Mater., 55, 2007, p. 4741. doi:10.1016/j.actamat.2007.04.044

[15] Zeng, H., Wu, Y., Zhang, J., Kuang, Ch., Yue, M., Zhou, S.: Progress in Natural Science: Materials International, 23, 2013, p. 18. doi:10.1016/j.pnsc.2013.01.003

[16] Phani, P. S., Vishnukanthan, V., Sundararajan, G.: Acta Mater., 54, 2006, p. 3333. doi:10.1016/j.actamat.2006.03.021

[17] Schafler, E., Steiner, G., Korznikova, E., Kerber, M., Zehetbauer, M. J.: Mater. Sci. Eng. A, 410-411, 2005, p. 169. doi:10.1016/j.msea.2005.08.070

[18] Hutchison, T. S., Reekie, J.: Phys. Rev., 83, 1951, p. 854.

[19] Wang, C. P., Liu, X. J., Ohnuma, I., Kainuma, R., Ishida, K.: JPEDAV, 25, 2004, p. 320. doi:10.1007/s11669-004-0150-5

[20] Rossiter, P. I.: The Electrical Resistivity of Metals and Alloys. Cambridge, Cambridge University Press 1987.

[21] Pops, H.: IEEE Elec. Insul. Mag., 11, 1995, p. 17. doi:10.1109/57.466412

[22] https://www.nde-ed.org/GeneralResources/Formula/ ECFormula/IACSConversion/IACS.htm

[23] Orolínová, M., Durišin, J., Durišinová, K., Danková, Z., Besterci, M., Ďurišin, M.: Chemical and Materials Engineering, 1, 2013, p. 60.

[24] Stobrawa, J. P., Rdzawski, Z. M.: Journal of Achievements in Materials and Manufacturing Engineering, 24, 2007, p. 35 . 